\title{
Awareness of gastrointestinal tract malignancies among the population of Lublin province (Eastern Poland) - A cross-sectional study
}

\author{
Monika Berbecka ${ }^{1, C-E \oplus}$, Małgorzata Kolasińska-Bzoma ${ }^{2, A-B, D \oplus}$, Ewa Kolasińska-Gliwa ${ }^{3, A-B, D \oplus}$,

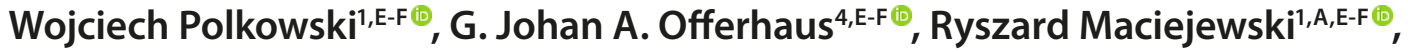 \\ Robert Sitarz ${ }^{1, A-F}$ () \\ ${ }^{1}$ Medical University, Lublin, Poland \\ ${ }^{2}$ Independent Public Primary Health Care, Parczew, Poland \\ ${ }^{3}$ Non-public Primary Health Care Facility, Józefów, Poland \\ ${ }^{4}$ Department of Pathology, University Medical Centre, Utrecht, The Netherlands \\ A - Research concept and design, B - Collection and/or assembly of data, C - Data analysis and interpretation, \\ $D$ - Writing the article, E-Critical revision of the article, F- Final approval of article
}

\begin{abstract}
Berbecka M, Kolasińska-Bzoma M, Kolasińska-Gliwa E, Polkowski W, Offerhaus GJA, Maciejewski R, Sitarz R. Awareness of gastrointestinal tract malignancies among the population of Lublin province (Eastern Poland) - A cross-sectional study. Ann Agric Environ Med. $2020 ; 469-475$. doi: $10.26444 /$ monz/114980
\end{abstract}

\section{Abstract}

Introduction. Currently, malignancies are the most severe medical problems worldwide. Numerous, already known risk factors in carcinogenesis could be potentially avoided. Some cancer risk factors have been recognized and have become the targets of primary prophylaxis.

Objective. The aim of the study was to ascertain the state of knowledge about risk factors, primary prevention and early detection of malignancies of gastrointestinal tract (GIT) in the urban and rural population of the Lublin province in Eastern Poland.

Materialas and method. The study was cross-sectional. The originally designed questionnaire was applied to the group of 1,352 patients, representatives of both the rural and urban environments of the Lublin province during random appointments with their general practitioner (GP).

Results. The study showed low awareness of the issues connected with GIT malignancies within the studied group. The problem was particulary apparent in the rural population.

Conclusions. In order to raise general awareness of cancer, different means should be applied in urban and rural populations. GPs and the media were found to have the leading rols in the promotion of primary prevention.

\section{Key words}

awareness of gastrointestinal malignancies, cancer prevention, primary health care, prophylaxis, risk factors

\section{INTRODUCTION}

According to the World Health Organization (WHO) there is a significant increase in the incidence of malignant tumours within the aging population. Cancer, being the second main cause of death worldwide, is one of the most significant health and economic issues for society [1]. In Poland, 25\% of deaths are oncology-related and the number of newlydiagnosed cancers annually exceeds 130,000 cases [2]. In comparison to the USA, the rate of Polish patients treated for early stages of cancer is still unsatisfactory (USA - 80\%, Poland -20\%), which is reflected in poor records of complete recovery after oncological treatment [3]. The overall 5-year relative cancer survival rates in Poland are only about $30 \%$ and are one of the lowest in Europe [4]. This problem also concerns gastrointestinal (GIT) malignancies which, despite the ongoing development of surgical techniques and multidisciplinary treatment, have a poor outcome.

Address for correspondence: Monika Berbecka, Medical University of Lublin, Poland E-mail: monikapilecka88@gmail.com

Received: 31.01.2019; accepted: 11.09.2019; first published: 30.09.2019
Generally, the concept of cancer and oncology in Poland continues to be stigmatized, which results in postponed diagnostics and non-radical treatment [5]. All actions focused on prevention, education and early detection are crucial. Cancers of the digestive tract result from exposure to environmental risk factors, a combination of specific genetic alterations and epigenetic changes $[6,7,8]$. Epidemiological studies show a strong relationship between the incidence and course of malignant diseases with various systemic and environmental factors. Scientists have concluded that in more than $80 \%$ of patients with cancer, environmental factors, leading to the development of tumour, can be identified [8]. In fact, to some degree, cancers of the digestive tract could be prevented by a healthy life style and early screening in a particulary vulnerable population.

Knowledge of risk factors provides opportunities for intervention and early prevention. Primary health care plays a leading role in early prevention [9]. It is a part of the novel approach to early prevention, to begin the anticancer battle in the patient's environment and direct neighbourhood. The surgery of the general practitioner (GP) is the best place for the meeting of medicine, a healthy approach to life-style, 
and information about risk factors and early sympthoms in carcinogenesis. In Poland, the GP is responsible for the promotion of healthy life-style, providing information about cancer risk factors and identification of its early symtoms. The diagnostic process and treatment of oncological patients is a challenging and important task in general practice. It appears that some patients, unless directly asked, do not complain about symptoms that are well-documented alarm symptoms of cancer. GPs need to be cautious, because delay in the cancer diagnosis worsens the prognosis of complete cancer cure, with more probable adverse effects and negative impact on the quality of life [10]. Therefore, the emphasis is placed on possible early prevention and early detection of cancers.

High cancer-related morbidity and mortality rates in Poland indicate the need to continue ongoing prevention programmes (Primary National Programme Against Cancer Diseases) and subsequent programsme aimed at promoting secondary cancer prevention, diagnosis and treatment. The success of these programmes depends on the initial steps of raising knowledge about cancers among the society [11], particulary among the population at high cancer risk. The more aware the patients are, the earlier the diagnosis, and a better final outcome of the oncological therapy.

It is estimated that treating patients with advanced cancer often requires palliative care, which causes an increase in financial expenses. Early prevention methods and improved early detection of cancer will result in treatment in the early stages of cancer, which should result in a cure rate of $50 \%$ of patients, and breaking the taboo in society that cancer, by definition, is an incurable disease $[12,13]$. This will also increase the level of public awareness and health education, and eliminate the fear of regular medical examinations.

\section{OBJECTIVE}

The study had two aims: 1) collect knowledge about awareness of gastrointestinal tract malignances among the population of the Lublin Province in Eastern Poland; 2) compare the awareness of upper and lower gastrointestinal tract malignances in the rural and urban populations, as well as in the age groups; 3) searching for methods of successful education and prevention of GIT malignances which could be easily applied to the population.

\section{MATERIALS AND METHOD}

The research was designed as a cross-sectional study devoted to patients from the rural and urban populations of the Lublin Province in situated in South-East Poland. The sudy was conducted on the territory of the province which is divided in 20 administrative districts. The province is agricultural with a sparse demographic tendency.

The study group consisted of patients who attended primary health care offices in four different communes of the Lublin province. The patients reported to a GP for various reasons and during the visit and examination agreed to complete an originally designed questionnaire consisting of 20 questions. Participation in the survey was voluntary and anonymous. In the questionnaire, the participants were asked about the most common and symptomatic gastrointestinal cancers: oesophageal, gastric, pancreatic, and colorectal cancer, as well as liver cancer, including hepatocellular carcinoma. Patients being treated due to a chronic diseases (e.g. diabetes mellitus, hypertension) and cancers, as well as those who had undergone endoscopic procedures in the past, were not excluded from the study group. The study was conducted from April 2010 - April 2011 (lyear) and involved 1,352 participants aged $24-87$ years.

The study participants represented the urban and rural population. The urban study population came from two main towns, Józefów and Parczew in the Biłgoraj and Parczew districts, respectively. The rural population came from villages of Sosnowica, Rudno, Radcze and Rudziniec.

Biłgoraj district, with its main town Józefów, is situated in the southern part of the Lublin province, in the Roztocze which is a range of hills in east-central Poland and western Ukraine. Biłgoraj district covers about $262.6 \mathrm{~km}^{2}$ and his 13,294 inhabitantss. The main town of Biłgoraj district, Józefów, is inhabited by 2,532 people. Parczew district is territorially one of the smallest districts $\left(146.2 \mathrm{~km}^{2}\right)$ with the least population in the Lublin Province (10 748). The rural participants came from Sosnowica village, inhabited by 2,750 people and known for its large forest complex. The villages of Rudno, Radcze and Rudzieniec are a part of one rural commune inhabited in total by 4,060 people.

The populations of both Józefów and Parczew districts are decresing, aging and characterized by a negative natural population growth factor. The level of education within the inhabitants of Józefów and Parczew districts is reported to be below the average for Lublin Province. Among the female population, $26.7 \%$ had completed primary education and only $16.8 \%$ higher education. Among males, $24.8 \%$ had completed primary education, but the majority (28.9\%), had only basic vocational education. The rate of unemployment in the area is approximately $7.6 \%$, and an increasing number of the inhabitants rely on social welfare benefits as their only source of income. $64.9 \%$ of the active population are employed in the agricultural sector (agriculture, forestry, hunting and fishing), $14.3 \%$ in industry and construction, $5.4 \%$ in the service sector (trade, vehicle repair, transport, accommodation and gastronomy, information and communication), and $0.9 \%$ work in the financial sector (finance and insurance, real estate). The income per capita in Józefów district is one of the lowest in the Lublin Province (circa. 813 zlotys = ca. 203 euros), and the average monthly gross salary is also lower than in the rest of the coutry (circa. 3,531 zlotys $=$ ca. 880 euros) $[14,15]$.

Patients who were demented or had difficulties with effective communication were excluded from participation in the study.

Study design. The study was based on the newly launched 'National Programme to Fight Cancer', published on 12.03.2010 by Ministry of Health of Poland (Dz.Urz. MZ.10.4.33) and aimed at increasing the vigilance of GPs against the cancer problem [5].

The study was approved by the Bioethics Committee of the Medical University in Lublin (KE-0254/73/201) and carried out between April 2010 - April 2011, with plans to repeated it in 5-years time. The study included 1,352 patients aged 24 - 87 years, and was conducted in four GP outpatients' clinics in the Lublin Province: Independent Primary Public Health Care Clinic in Parczew, Health Centre in Sosnowica, Health Centre in Rudno and the 'Our Health' Primary Care Clinic 
in Józefów and its branch in Długi Kąt. The total number of patients registered in all above-mentioned health centres was 15,328 and the study was conducted on $8.82 \%$ of them.

The research was not adverised among the population in the form of information posters, bills or through the Church. The study was performed in each of the health care centres by the participants completing the questionnaires during a random medical appointment under the supervision a person involved in the study. Participation was voluntary, anonymous, and supervised by a competent assistant.

Research tool. The research tool was an originally designed questionnaire consisting of 20 questions (attached as supplementary material). The questionnaire was anonymous and divided in three parts in order to collect data connected with: a) basic demography, b) awareness of upper and lower gastrointestinal tract malignancies and c) application of screening and preventive tools offered free of charge by the government. In the questionnaire, the particiupants were asked about the most common and symptomatic gastrointestinal cancers: oesophageal, gastric, pancreatic, and colorectal cancer, as well as liver cancer, including hepatocellular carcinoma. Patients being treated due to chronic diseases (e.g. diabetes mellitus, hypertension) and cancers, as well as those who had undergone endoscopic procedures in the past, were not excluded from the study group. The exclusion criteria were: dementia and concurrent illness and other factors interfering with effective communication.

The first part of survey consisted of questions about gender, age, place of residence, education and place of work (5 questions). The participants were divided into four age groups: $21-30,31-40,41-60$, and over the age of 61 . The second part of the study ( 8 consecutive multiple choice questions) referred to: family history of gastrointestinal tract cancer, awareness of main risk factors for upper and lower gastrointestinal tract cancers, the s symptoms, protective factors, diagnostic methods, screening, availability of screening programmes, and the source of patients' information about cancer. The statistics of answers to the questions were compared with demographical data, such as gender, place of residence and level of education. In the third part of the questionnaire (7 questions), the respondents were asked about their health habits: type of meat they consumed, level of physical activity, smoking, alcohol consumption, maintaining body weight and generally healthy lifestyle. The last 2 questions are connected with the prophylaxis of malignancies.

The study was evaluated and approved by the Bioethics Committee of Medical University of Lublin (KE-0254/73/201).

Statistical analysis. The research results were statistically analyzed by Statistica (Statsoft, version 9.0, USA). $\chi 2$ Person's test was used to measure dependences between the variables. Additionally, some of the dependences were illustrated according to correspondence analysis.

\section{RESULTS}

Respondents' characteristics. The studied group comprised 1,352 patients. The majority - $929(68.7 \%)$, came from rural areas and the rest $-429(31.3 \%)$ from urban areas. $505(37.4 \%)$ respondents were are male and $847(62.7 \%)$ female. The statistics concerning level of education revealed that high education was achieved by 188 patients (13.9\%), secondary education by 536 (39.6\%), primary education by 336 (24.9\%), and other education (incomplete education, incomplete education with apprenticeship, occupations from generationto-generation) - 291 (21.5\%) participants. 5 age subgroups were distinguised: $21-30$ years - 222 (16.4\%), 31-40 - 256 (18.9\%), 41-50 - 270 (19.97\%), 51-60 - 260 (19.23\%), >60 years $-344(25.4 \%)$ (Tab. 1).

Table 1. Respondents' characteristics

\begin{tabular}{llc}
\hline Variable & $\mathbf{n}$ & $\%$ \\
\hline All cases & 1352 & 100 \\
\hline Gender & 505 & 37.35 \\
\hline male & 847 & 62.65 \\
\hline female & & \\
\hline Place of residence & 929 & 68.71 \\
\hline rural & 423 & 31.29 \\
\hline urban & & \\
\hline Education & 337 & 24.93 \\
\hline elementary/incomplete & 536 & 39.65 \\
\hline secondary & 188 & 13.91 \\
\hline higher education & 291 & 21.52 \\
\hline other & & \\
\hline Age & 222 & 16.42 \\
\hline $21-30$ & 256 & 18.94 \\
\hline $31-40$ & 270 & 19.97 \\
\hline $41-50$ & 260.44 \\
\hline $51-60$ & & \\
\hline$>60$ & 344 & \\
\hline
\end{tabular}

Degree of awareness of GIT malignances. The degree of gastrointestinal malignancies awareness were analyzed according to the following factors: 1) place of residence (rural/ urban), 2) gender, 3) education and 4) age, and statistically analysed. All the relationships were found to be statistically significant $(\mathrm{p}<0.05)$.

Primarily, it was found that the relationship between the awareness of GIT malignances and the place of residence was at the significance level $\mathrm{p}<0.05$. The results also showed that high awareness of GIT malignances was observed 2.1 times more often in urban areas, compared to rural areas. In the latter, inhabitants with a low level of awareness about GIT malignances were observed 1.5 times more often than in urban areas.

Moreover, the relationship between the awareness of GIT malignances and gender at a significant level was proved. Among women, a high level of awareness of GIT malignances was observed 1.7 times more frequently than among men.

Furthermore, a significant relationship $(\mathrm{p}<0.001)$ was observed between the awareness of GIT malignances and education level (Tab. 2). People with a lower education (elementary and others) had a lower awareness of GIT malignances than those with higher education (universities and secondary schools). The largest difference was observed between the groups with higher and elementary education: those with higher education were 5 times more likely to have higher levels of awareness of GIT malignancies than those with elementary education. 
Table 2. Correlation between education and level of cancer awareness

\begin{tabular}{lccccc}
\hline \multicolumn{5}{c}{ Education $(\mathrm{p}<0.001)$} \\
\hline Awareness & $\begin{array}{c}\text { higher } \\
\text { education }\end{array}$ & secondary & elementary & $\begin{array}{c}\text { other education/ } \\
\text { incomplete }\end{array}$ & total \\
\hline Low & $94(50.0 \%)$ & $329(61.4 \%)$ & $303(89.1 \%)$ & $219(75.3 \%)$ & 945 \\
\hline High & $94(50.0 \%)$ & $207(38.6 \%)$ & $34(10.1 \%)$ & $72(24.7 \%)$ & 407 \\
\hline
\end{tabular}

Additionally, there was a statistically significant relationship between the awareness of GIT malignances and age (Tab. 3). The highest percentage of low awareness was observed in the group aged $>60$ years $(264 ; 76.7 \%)$, while the highest awareness of cancers was found in the group aged $41-50$ years $(92 ; 34.1 \%)$.

Table 3. Relationship between age and level of cancer awareness

\begin{tabular}{lcccccc}
\hline \multicolumn{7}{c}{ Age $(p=0.007)$} \\
\hline $\begin{array}{l}\text { Aware- } \\
\text { ness }\end{array}$ & $21-30$ & $31-40$ & $41-50$ & $51-60$ & $>60$ & total \\
\hline Low & $157(70.7 \%)$ & $175(68.4 \%)$ & $178(65.9 \%)$ & $183(70.4 \%)$ & $264(76.7 \%)$ & 945 \\
\hline High & $65(29.3 \%)$ & $81(31.6 \%)$ & $92(34.1 \%)$ & $77(29.6 \%)$ & $80(19.7 \%)$ & 407 \\
\hline
\end{tabular}

Relationships between place of residence, level of education, and awareness of cancer. In order to determine the main influence on the awareness of GIT malignances, 2 groups of participants were compared: those with higher education living in rural and urban areas, respectively. Analysis revealed that participants with higher education in urban areas had a significantly higher level of awareness of GIT malignances than those with higher education living in rural areas. Thus, the place of residence had a stronger influence on awareness of GIT malignances than the education level $(\mathrm{p}<0.001)$ (Tab. 4.)

Table 4. Place of residence and gender impact on cancer awareness

\begin{tabular}{lccc}
\hline Place of residence $(p<0.001)$ & & & \\
\hline Awareness & rural & urban & total \\
\hline Low & $721(77.6 \%)$ & $224(52.9 \%)$ & 945 \\
\hline High & $208(22.34 \%)$ & $199(47.0 \%)$ & 407 \\
\hline Gender $(p<0.001)$ & & & \\
\hline Awareness & man & women & total \\
\hline Low & $400(79.2 \%)$ & $545(64.3 \%)$ & 945 \\
\hline High & $105(20.8 \%)$ & $302(35.7 \%)$ & 407 \\
\hline
\end{tabular}

Source of cancer information. In the rural areas, most residents declared that their main source of information about cancers are: 1$)$ media $(40.0 \%-372$ participants had a TV-set) and 2) the GP (215;23.1\%). Among the urban population, the most popular source of information about cancer is from leaflets $(93 ; 21.9 \%)$. The results show that the participants with elementary education in rural areas indicated their GP as the main source of cancer information. Participants with higher and secondary education in rural areas indicated TV as the main source of cancer information, whereas participants from urban areas indicated leaflets as their main source of information.

Subjective and objective assessment of cancer awareness. Subjective assessment was an indication of the participants, and the objective assessment was the result of analysis of answers to targeted questions in the survey. The result of the subjective assessment of own cancer awareness was: 1) good - 333 participants (24.6\%) and 2) poor - 1019 (75.4\%) participants. There was no significant correlation between subjective assessment, gender and age ( $p>0.05)$. However, there was a statistically significant relationship between subjective assessment and education level $(\mathrm{p}<0.05)$. Among the participants with higher education, a subjective knowledge of cancer awareness was declared more often as good 56 (29.8\%).

Finally, significant dependence was found between subjective and objective knowledge of cancer prevention $(\mathrm{p}<0.01)$. Nevertheless, the correlation was weak (Fi index $\mathrm{Fi}=0.08 ; 0$ - no correlation, 1 - total correlation).

\section{DISCUSSION}

Major finding of the study. The results of the study indicated that the reduced effectiveness of prevention and early anticancer therapy in Poland may result from a considerable disproportion in awareness of gastrointestinal tract malignancies between the rural and urban populations. These disproportions are of multifactorial character and are the result of differences in the level of education, access to mass media, medical institutions, or even gender. The study clearly shows that the rural population Lublin Province was much less aware of gastrointestinal tract malignancies and prevention methods than the urban population. Interestingly, the study shows the very important role of both the general practitioner/ family doctor and television in promoting primary prevention in the rural environment. Whereas brochures, flyers and the press seems to work better in urban areas in promoting health lifestyle guidelines. This finding was of particular importance as it concerned the majority of inhabitants of the Lublin Province. Most of the Lublin Province is rural where knowledge about health behaviour and malignancies is very low, even among the young generation. Interestingly, women had better knowledge about cancer prevention compared to men, a fact demonstrated in numerous studies in rural as well as urban areas [16]. Taking into consideration fact that, as happens also in the current study, women are better educated and have higher awareness about malignancies, a well- based conception could be to re-educate them in order to transfer the knowledge to the family and local community. The findings of this study are comparable to that by Lynes K., et. al. where the awareness of lifestyle risk factors for colorectal cancer was shown to correlate with age and level of education [17]. The authors proved the need to improve the awareness of young people - the group that would benefit most from the actions aimed at raising awareness of malignancies. Willems B., et al. also emphasize that people with a higher education level are more likely to involve themselves in cancer screening on their own initiative, while people with less education participate rather on the initiative of the medical environment [18].

Current state of knowledge. The idea of the presented study originated from a publication in 2012 which estimated cancer frequency and mortality in Europe [5]. The publication revealed relevant variations within the countries that could be explained by differences in the national health system policies. The variability in incidences of particular cancers 
within Europe was found to depend on various risk factors and on inequalities in education. Therefore, the authors concluded that there is a need to tackle the cancer problem on a local level, in order that all the actions can be adjusted to the characteristics of the region.

In general, cancers of the digestive tract result from exposure to environmental risk factors, a combination of specific genetic alterations and epigenetic changes. It is also known that tumours of gastrointestinal track grow from existing, molecularly alterated precancerous lesions that are stimulated by chronic inflammation and suppression of the immune system [19]. Therefore, high risk populations might be prophylactically treated with non-steroidal antiinflammatory drugs $[20,21]$. In the modern approach, precancerous lesions need to be targeted in cancer prevention, because then the neoplastic processes might be stopped at the very beginning, before the progression of intraepithelial neoplasia [22]. However, to-date, too little is known about the molecular mechanisms involved in cancerogenesis to introduce such therapeutic management.

Behaviour that carries the risk for GIT cancer have also become a promising area of interest for practitioners and researchers. Environmental risk factors, such as smoking and unhealthy diet, are known to be responsible for over $50 \%$ of cancers, with $30 \%$ attributed to tobacco, $30 \%$ to dietary mistakes, and the remaining $30 \%$ to environmental factors.

Advances in the knowledge of carcinogenesis would result in the identification of a growing number of risk factors and make it possible to avoid them. Cancer control should consist of clear, widespread prevention programsme, screening, early diagnosis programmes and improved treatment [3]. Primary prevention requires the strong support of the public health system. The money spent at present on cancer treatment and prevention are regarded as being insufficient [12] and more resources and time should be devoted to primary prevention where, with minimal effort, better results could be achieved.

Cancer prevention also involves secondary prevention, the early detection of malignancies through screening and treatment of lesions before metastasis occurs. Primary prevention includes reduced exposure to cancer-promoting environmental factors - a huge task not only for physicians but also organizations and public health policy.

Importance of prevention and screening for colorectal cancer (CRC) patients outcome. CRC is one of the most commonly diagnosed GIT cancers and causes of death worldwide which, however, can be detected in asymptomatic patients at a curable stage. Lower mortality among patients who undergo screening is well-supported by research. The usage of colonoscopy in CRC screening results in the detection of precancerous polyps that can be directly removed during the procedure [23]. The findings of Dinaux A.M et al. strogly indicate that screened patients have a lower rate of CRC recurrence, longer disease-free survival and overall survival [24]. Another novelty is the pursuit of screening individualization - tailoring screening to the risk of malignancy. According to PDQ Cancer Information, the advantages of screening might be improved by fitting the recommended screening test to a patient's degree of CRC risk. For example, in a subgroup of young women, sigmoidoscopy is recommended instead of colonoscopy [25].
Role of the GP in screening for gastrointestinal cancer. Along with the ageing population, the number of GIT cancer patients and cancer survivors is increasing. Traditionally, the management of malignancies is performed by in-hospital specialists. Nowadays, there is a trend to relocate cancer care from the hospital environment to the primary care setting, in the hope that it will stimulate personalized and integrated care, increase cost-effectiveness and better meet the patients' needs and expectations. Authors of the GRIP study underline that in countries where the GP is the 'gatekeeper' in the health care system (e.g. The Netherlands), the GP has a long-lasting personal relationship with the patient, is up-to-date with the patients' medical history, and preferences which translates into better doctor-patient relationships and confidence during the treatment process. Therefore, patients, health care workers, government and professional organisations suggest a more prominent role of the GP in the therapeutic process of oncological diseases [26].

The PEARL study also highlight role of the GP for cancer screening and demonstrated that people encouraged by a GP were more likely to respond to a screening invitation. Moreover, patients who ignored reminder letters from prevention centres might still have reacted to an endorsed reminder from their GP [27].

The quality of patient-GP communication is also a subject of observant research and studies indicate the following barriers in GP-patient relationships: 1) fear of an adverse diagnosis (patients ashamed to report alarm symptoms of CRC), 2) time (patient worried about wasting the doctor's time and minimizing the symptoms), 3) lack of professional knowledge (searching on the Internet and asking friends/ acquaintances for about the disease). The proportion of individuals who reported barriers was higher among the youngest age group [28]. Such barriers in communication, except from lack of time and shyness, could also be unsuitable and too medical language, outfit, presence of family, or other medical personnel.

The role of the GP in oncological education and prevention is indisputable. Patients found it relevant to consult the results of their investigations with their primary care physician. Nevertheless, it seems that cancer-related problems are more eagerly discussed with oncologists [29].

Progress in cancer treatment is evident. An important point from the literature is that cancer, as a process that may be developing for decades prior to its detection, requires a long time for preventive interventions to be considered. It seems that the most effective method of reducing cancer incidence is primary prevention. Prevention was found to be more effective and less expensive than treatment [30,31]. The process of GIT cancerogenesis is very long and it favours the promising effects of cancer prophylaxis as it allows sufficient time for early prevention. However, the prophylaxis needs to be started at least 10 years before the anticipated age of cancer occurrence. Prophylaxis requires the involvement of patients which depends on their understanding and awareness of the subject. At this point, the role of the primary care doctor is pivotal.

What this study adds. The future of the battle with GIT malignancies should focus on prevention and self-care linked to holistic health. Various health promotion programmes should present a message designed by local scientific centres for local society groups. Promotion should be designed for 
both the urban and rural populations, using different routes to motivate public opinion, especially among young people. Attention should be paid to possible ways of raising awareness of cancer diseases by creating new educational programmes, knowledge contests, and media campaigns. Emphasis should be placed on the regional media as well as on family physicians [11], who could promote health education among their patients. It is therefore essential, as far as possible, to plan and introduce the habit of family doctors meeting with their patients to talk about the most frequently occurring health problems (cardiovascular disease and cancer). Such meetings would result in improving knowledge about illnesses and possible cancer prevention, and also break the patients' fear of doctors, as well as the taboo that cancer is a lethal disease [32].

The main message of the presented study is that in the Lublin Province the management of GIT malignancies should focus mainly on primary and seconadary prevention. In Poland, treatment of the cancers of the digestive track does not differ from the European standards, but awareness of these cancers in eastern areas was among the lowest in Europe. Therefore, there is a need to introduce more informative activities that would depend on behavioural, political and social characteristics of the targeted audience $[33,34,35]$.

The means of the efficient cancer prevention include diet, life style modification, chemoprevention, as well as genetic interventions in order to eliminate oncogenes or repair the impaired suppressors [36, 37, 38].

Limitations of the study. The questionnaire used comprised a limited number of questions about GIT malignancies, and were mostly devoted to gastric and colon cancers. Although the questionnaire was completed on a voluntary basis, the composition of the study group did not precisely represent the general population in the Lublin Province. Moreover, the participants were interviewed during their random visit to their GP, and the question arises about whether such a group reflected the general population of the province. In spite of these limitations, the obtained results are extremely important for developing health promotion programmes focused on healthy lifestyles for the Polish population.

\section{CONCLUSIONS}

The population of the Lublin province showed a very low level of knowledge about health behavior and GIT malignancies in general. Among this population, awareness of lifestyle risk factors for CRC correlate with age and level of education: compared to men, middle-aged women (41-50 years) were better educated, were better informed about cancer prevention, and had higher awareness in the area of GIT malignancies. The low level of health-promoting awareness among the young population (21-30 years) in the Lublin Province is surprising and worrisome. The study revealed that higher awareness in the area of GIT malignancies was correlated with urban areas of living - high awareness was observed 2.1 times more often in urban areas compared with rural areas. Knowledge in rural areas is passed mostly by GPs and the media, whereas among the residents of urban areas, it was by brochures, leaflets and the press - these are also possible ways to propagate anti-cancer prevention.
The GP practice seems to be a convenient place to conduct questionnaire surveys and population research.

The results of the presented study indicated that there is an urgent need to develop programmes that promote a healthy lifestyle and spread anti=cancer awareness in the Lublin Province. From the experience gained, the authors state that special attention should be paid to the inhabitants of rural areas as they seemed to be the least aware of the cancer problem. The age subgroups should encompass the elderly (>61 years) and the young generation (21-30 years), as they seemed to be especially unaware. Hopefully, these conclusions will influence future campaigns and educational cancers programmes.

\section{Acknowledgements}

The study was partly supported by the Ministry of Science and Higher Education in Warsaw, Poland [Grant No. NN402423838]. The authors express their thanks to dr M. Skierucha for critical review of the manuscript.

\section{Competing interests}

The authors declare no competing interests.

\section{REFERENCES}

1. Ferlay J, Colombet M, Soerjomataram I, Dyba T, Randi G, Bettio M, Gavin A, Visser O, Bray F. Cancer incidence and mortality patterns in Europe: Estimates for 40 countries and 25 major c ancers in 2018. Eur J Cancer. 2018 Nov; 103: 356-387. https://doi.org/10.1016/j. ejca.2018.07.005

2. International Agency for Research on Cancer. Available from: http:// www-dep.iarc.fr/WHOdb/WHOdb.htm. 2016; (access: 09.06.2019)

3. Syczewska-Weber K, Rucinski P. The main challenges of Polish oncology. Public Health Rep. 2008; 123: 655-63. https://doi. org/10.1177/003335490812300517

4. Rossi S, Baili P, Capocaccia R, Caldora M, Carrani E, Minicozzi P, et al. EUROCARE-5 Working Group; EUROCARE-5 study on cancer survival in Europe 1999-2007: Database, quality checks and statistical analysis methods. Eur J Cancer. 2015 Oct; 51(15): 2104-2119. https:// doi.org/10.1016/j.ejca.2015.08.001. Epub 2015 Sep 26. Avaliable from: https:// linkinghub.elsevier.com/retrieve/pii/S0959-8049(15)00776-5/, (access: 09.06.2019)

5. "National Program for the Control of Cancer", Dz.Urz.MZ.10.4.33, 2010; available from: http://bipold.mz.gov.pl/index? $\mathrm{mr}=\mathrm{m} 12101 \&$ $\mathrm{ms}=\& \mathrm{ml}=\mathrm{pl} \& \mathrm{mi}=210 \& \mathrm{mx}=0 \& \mathrm{mt}=\& \mathrm{my}=274 \& \mathrm{ma}=14925 ; \quad$ (access: 09.06.2019)

6. Sapienza C, Issa JP. Diet, Nutrition, and Cancer Epigenetics. Annu Rev Nutr. 2016 Jul 17; 36: 665-81. https://doi.org/10.1146/annurevnutr-121415-112634

7. Milne AN, Sitarz R, Carvalho R, Carneiro F, Offerhaus GJ. Early onset gastric cancer: on the road to unraveling gastric carcinogenesis. Curr Mol Med. 2007; 7: 15-28.

8. Colditz GA, Wei EK. Preventability of Cancer-The Relative Contributions of Biologic and Social and Physical Environmental Determinants of Cancer Mortality, Annu Rev Public Health. 2012 Apr; 33: 137-156. https://doi.org/10.1146/annurev-publhealth-031811-124627

9. Cheung WY, Neville BA, Cameron DB, Cook EF, Earle CC. Comparisons of patient and physician expectations for cancer survivorship care. J Clin Oncol. 2009; 27: 2489-95. https://doi.org/ 10.1200/JCO.2008.20.3232

10. Jensen H, Nissen A, Vodsted P. Quality deviations in cancer diagnosis: prevalence and time to diagnosis in general practice. BJ Gen Pract. 2014 Feb; 64(619): e92-8. https://doi.org/10.3399/bjgp14X677149

11. The Act of November 3, "National Program Against Cancer DiseasePoland 2016-2024” Dz.U. z 2015 r. Nr 208, poz. 1165. 2015. Available from: https://www.gov.pl/web/zdrowie/narodowy-programzwalczania-chorob-nowotworowych-na-lata-2016-2024; (access: 09.06.2019)

12. Frieden TR, Myers JE, Krauskopf MS, Farley TA. A public health approach to winning the war against cancer. Oncologist. 2008; 13: 1306-13. https://doi.org/ 10.1634/theoncologist.2008-0157 
13. Bailar JC, Gornik HL. Cancer undefeated. N Engl J Med. 1997; 336: 1569-74. https://doi.org/ 10.1056/NEJM199705293362206

14. Central Statistical Office in Poland, Information Portal. Available from: http://stat.gov.pl/; (access: 09.06.2019)

15. Poland in numbers- available from: http://www.polskawliczbach.pl/; (access: 09.06.2019)

16. Binkowska-Bury M, Kruk W, Szymanska J, Marc M, Penar-Zadarko B, Wdowiak L. Psychosocial factors and health-related behavior among students from South-East Poland. Ann Agric Environ Med. 2010; 17(1): 107-13.

17. Lynes K, Kazmi SA, Robery JD, Wong S, Gilbert D, Thaha MA. Public appreciation of lifestyle risk factors for colorectal cancer and awareness of bowel cancer screening: A cross-sectional study. IJ Surg. 2016, 36 (A): 312-318. https://doi.org/10.1016/j.ijsu.2016.11.002

18. Willems B, Bracke P. Participants, Physicians or Programmes: Participants' educational level and initiative in cancerscreening Health Policy. 2018 Apr; 122(4): 422-430. https://doi.org/10.1016/j. healthpol.2018.02.001

19. Pilecka M, Brzozowska A, Mazurkiewicz A. Programmed death receptor PD-1 as a potential target in anticancer therapy. Onkologia i Radioterapia - Medical Project, 2015; 2: 48-55.

20. Van Heumen BW, Roelofs HM, Vink-Börger ME, Dekker E, MathusVliegen EM, Dees J, et al. Ursodeoxycholic acid counteracts celecoxib in reduction of duodenal polyps in patients with familial adenomatous polyposis: a multicentre, randomized controlled trial. Orphanet J Rare Dis. 2013 Aug 6; 8: 118. https://doi.org/ 10.1186/1750-1172-8-118.

21. Dulai PS, Singh S, Marquez E, Khera R, Prokop LJ, Limburg PJ, et al. Chemoprevention of colorectal cancer in individuals with previous colorectal neoplasia: systematic review and network meta-analysis BMJ 2016; 355 doi: https://doi.org/10.1136/bmj.i6188

22. Limoges-Gonzalez M, Al-Juburi A. Anal Intraepithelial Neoplasia. J Clin Gastroenterol. 2017 Mar; 51(3): 203-207. https://doi.org/10.1097/ MCG.0000000000000721

23. Dekker E, Rex DK. Advances in CRC prevention: screening and surveillance. Gastroenterology. 2018 Feb 15. pii: S0016-5085(18)302191. https://doi.org/ 10.1053/j.gastro.2018.01.069

24. Dinaux AM, Leijssen LGJ, Bordeianou LG, et al. The Influence of Screening on Outcomes of Clinically Locally Advanced Rectal Cancer. J Gastrointest Surg. 2018 Jun; 22(6): 1052-1058. https://10.1007/s11605018-3666-4

25. Colorectal Cancer Screening (PDQ $\left.{ }^{\circ}\right)$ : Health Professional Version, Feb 2018 - available from: https://www.ncbi.nlm.nih.gov/books/ NBK65825/ (access: 09.06.2019)

26. Perfors IAA, Helsper CW, Noteboom A, et al. Randomised controlled trial protocol (GRIP study): examining the effect of involvement of a general practitioner and home care oncology nurse after a cancer diagnosis on patient reported outcomes and healthcare utilization. BMC Cancer. 2018; 18: 132. https://doi.org/10.1186/s12885-018-4005-6.

27. Benton SC, Butler P, Allen K, et al. GP participation in increasing uptake in a national bowel cancer screening programme: the PEARL project. B J Cancer 2017; 116: 1551-1557. https://doi.org/ 10.1038/bjc.2017.129

28. Jarbøl DE, Rasmussen S, Svendsen RP, et. al. Barriers to contacting general practice with alarm symptoms of colorectal cancer: a population-based study. Fam Pract. 2018 Jul 23; 35(4): 399-405. https:// doi.org/ 10.1093/fampra/cmx117

29. Suija K, Kordemets T, Annuk K, Kalda R. The Role of General Practitioners in Cancer Care: A Mixed Method Design. J Cancer Educ. 2016; 31: 136-141. https://doi.org/10.1007/s13187-015-0834-z

30. KatzkeVA, Kaaks R, Kühn T.Lifestyle and cancer risk. Cancer J.2015 MarApr; 21(2): 104-10. https://doi.org/10.1097/PPO.0000000000000101

31. Bray F, Jemal A, Torre LA, Forman D, Vineis P. Long-Term Realism and Cost-Effectiveness: Primary Prevention in Combatting Cancer and Associated Inequalities Worldwide; J Natl Cancer Inst. 2015 Dec; 107(12): djv273. https://doi.org/10.1093/jnci/djv273

32. Chipidza FE, Wallwork RS, Stern TA. Impact of the Doctor-Patient Relationship; Prim Care Companion CNS Disord. 2015; 17(5): 10.4088/ PCC.15f01840. https://doi.org/10.4088/PCC.15f01840

33. Seifart C, Hofmann M, Bär T, Knorrenschild JR, Seifart U. Breaking bad news-what patients want and what they get: evaluating the SPIKES protocol in Germany. Ann Oncol. 2014; 25(3): 707: 711. https:/doi. org/10.1093/annonc/mdt582

34. Montazeri A, Tavoli A, Mohagheghi MA, Roshan R, Tavoli Z. Disclosure of cancer diagnosis and quality of life in cancer patients: should it be the same everywhere? BMC Cancer. 2009; 9: 39. https:// doi.org/10.1186/1471-2407-9-39

35. STROBE Statement- available from: https://www.strobe-statement.org/ fileadmin/Strobe/uploads/checklists/STROBE_checklist_v4_crosssectional.pdf/; (access: 09.06.2019)

36. Kushi LH, Doyle C, McCullough M, Rock CL, Demark-Wahnefried W, Bandera EV, et.al. American Cancer Society Guidelines on nutrition and physical activity for cancer prevention: reducing the risk of cancer with healthy food choices and physical activity. CA Cancer J Clin. 2012 Jan-Feb; 62(1): 30-67. https://doi.org/10.3322/caac.20140

37. Logan J, Bourassa MW. The rationale for a role for diet and nutrition in the prevention and treatment of cancer. Eur J Cancer Prev. 2018 Jul; 27(4): 406-410. https://doi.org/10.1097/CEJ.0000000000000427

38. Kushi LH, Doyle C, McCullough M, Rock CL, Demark-Wahnefried W, Bandera EV, et al. American Cancer Society Guidelines on nutrition and physical activity for cancer prevention: reducing the risk of cancer with healthy food choices and physical activity. American Cancer Society 2010 Nutrition and Physical Activity Guidelines Advisory Committee. CA Cancer J Clin. 2012 Jan-Feb; 62(1): 30-67. https://doi. org/10.3322/caac. 20140 